\title{
GPT2 Gene
}

National Cancer Institute

\section{Source}

National Cancer Institute. GPT2 Gene. NCI Thesaurus. Code C38508.

This gene plays a role in amino acid metabolism, liver gluconeogenesis and the homeostasis of fatty acid metabolism and storage. 